\title{
Particularities of cardiovascular rehabilitation in patients with chronic cor pulmonale
}

Adriana Iosip ${ }^{1}$, Bogdan Caloian ${ }^{1}$, Florina Frîngu ${ }^{1}$, Dumitru Zdrenghea ${ }^{1}$, Dana Pop ${ }^{1}$

Corresponding author: : Bogdan Caloian, E-mail address: bogdan912@yahoo.com

\section{Abstract}

Chronic cor pulmonale is defined as right ventricular hypertrophy and/or dilatation, secondary to pulmonary hypertension, as a result of a lung disease. In addition to therapeutic options, physical exercise and cardiovascular rehabilitation determine an increase in the exercise capacity and an improvement of psychosomatic health. Cardiopulmonary rehabilitation is defined as a complex intervention based on an extensive evaluation of the patient, followed by individualized therapy that includes but is not limited to physical exercise, education, lifestyle changes. It is recommended that all clinicians take into consideration cardiopulmonary rehabilitation and physical exercise as adjuvant therapy in these patients.

Key words: cor pulmonale, pulmonary hypertension, rehabilitation program, health-related quality of life,

\section{Introduction}

Chronic cor pulmonale is defined as right ventricular hypertrophy and/or dilatation, secondary to pulmonary hypertension, as a result of a lung disease (parenchymal or vascular) from the origin of the pulmonary artery to the entry of the pulmonary veins into the left atrium. In the general population, chronic obstructive pulmonary disease is the main cause of chronic cor pulmonale, because of the high incidence and prevalence of chronic bronchitis, and especially bronchitis secondary to smoking [1]. Worldwide, more than 251 million cases of chronic obstructive pulmonary disease (COPD) have been recorded, the number of deaths caused by this disorder being estimated at 3.17 million [2]. Parenchymal lung diseases or bronchial diseases (pulmonary tuberculosis, bronchiectasis, sarcoidosis, pneumoconiosis, etc.) rank second [3].

Obviously, one of the consequences of this disease is the development of pulmonary hypertension. Pulmonary hypertension is characterized by a progressive increase in pulmonary artery pressure and pulmonary vascular resistance that may lead to right heart failure and death. Regardless of the type of pulmonary hypertension, patients have progressive dyspnea and decreased exercise tolerance. The treatment of cor pulmonale currently involves drug therapy of the underlying pulmonary disease as well as pulmonary hypertension. In addition to these pharmacological options, physical exercise and pulmonary rehabilitation contribute to the improvement of the exercise capacity, WHO functional class, maximal oxygen consumption and resting heart rate $[4,5,6]$.
For the functional classification of patients with pulmonary hypertension, WHO classes are used, which are characterized as follows:

- Class I - patients with pulmonary hypertension who have no limitations of physical activity. Usual physical activity does not cause dyspnea, fatigue, chest pain or syncope.

- Class II - patients with pulmonary hypertension who have a slight limitation of physical activity. They have no symptoms at rest. Usual physical activity causes dyspnea and fatigue, chest pain or syncope.

- Class III - patients with pulmonary hypertension who have a marked limitation of physical activity. They have no symptoms at rest. Less than usual physical activity causes dyspnea and fatigue, chest pain or syncope.

- Class IV - patients with pulmonary hypertension who cannot perform physical activity without symptoms. These patients have signs and symptoms of heart failure. Dyspnea and fatigue may also occur at rest. Discomfort is increased by any physical activity [7].

It has also been demonstrated that physical exercise can improve quality of life and ameliorate depression and fatigue. It is recommended that all clinicians indicate pulmonary rehabilitation and physical exercise as adjuvant therapy in these patients because benefits are obvious $[4,8,9,10,11,12,13]$. Thus, cardiopulmonary rehabilitation can reduce dyspnea, increase exercise tolerance and improve healthrelated quality of life in all chronic respiratory disorders. 
Cardiovascular rehabilitation is defined as a complex intervention based on an extensive evaluation of the patient, followed by individualized therapy that includes but is not limited to physical exercise, education, lifestyle changes. All this is aimed at improving the physical and mental condition of patients with chronic respiratory disease, and at promoting long-term adherence to health-related behavior [14]. The team involved in the rehabilitation programs is complex. It includes, in addition to a cardiologist or internist, a kinesiotherapist, a nutritionist, a psychologist.

Regarding lifestyle changing, important recommendations related to nutrition are necessary $(<5 \mathrm{~g}$ salt/day, a diet rich in fruits, vegetables, cereals), as well as avoiding stress, excessive alcohol consumption, infections. Vaccination against pneumococcal pneumonia and influenza virus is recommended. For patients wishing to travel by air, who are in WHO class III-IV or have an arterial oxygen pressure $<60 \mathrm{mmHg}, \mathrm{O} 2$ supplementation is recommended [15].

In chronic cor pulmonale, a real vicious circle is created: dyspnea occurring during exercise leads to avoidance of physical activity, which favors cardiorespiratory system as well as skeletal muscle deconditioning, with the development of important psychological disorders (depression, anxiety, preoccupation with symptoms), and finally aggravation of dyspnea. Although initially, physical exercise was contraindicated in these patients, the results of clinical trials have led to a change in this position. Mereles et al. conducted the first randomized trial to assess the effects of physical exercise in chronic pulmonary hypertension patients stabilized by drug therapy [16]. They proposed a physical training program where the patients were hospitalized during the first 3 weeks and performed supervised physical exercises 7 days a week. The physical training program had 3 components: cycling on an ergometer at $60 \%$ up to $80 \%$ of the maximum heart rate for 10 up to 25 minutes, walking on flat or sloping ground for 60 minutes, 5 days a week, and lifting light weights for 30 minutes, 5 days a week. All patients were supervised by a physiotherapist and received sports education. Over the next 12 weeks, outside the hospital setting, the patients were asked to cycle for 15 up to 30 minutes a day, 5 days a week, to continue respiratory training and weight lifting, with periodic follow-up by phone [16]
Gruning et al., in 2012, used the same training program in a trial that included 183 patients with pulmonary hypertension (pulmonary arterial hypertension, chronic thromboembolic hypertension and pulmonary hypertension secondary to left heart disease) [9]. This prospective study investigated patients with severe chronic pulmonary hypertension who performed physical and respiratory training in addition to specific medication between January 2005 and October 2010 [9]. These patients were in WHO functional class II-IV. The patients had to be stable and compensated, on optimal medication for at least 2 months prior to their enrollment in the study [9].

The patients attended a program specially designed for patients with pulmonary hypertension, with physical exercise for 1.5 hours a day (in intervals distributed throughout the day), comprising a training interval on the cycle ergometer at a low power (10-60 W), 7 days a week, walking, lifting light weights (500-1000 g) involving a single muscle group, and a breathing exercise, 5 days a week. Maximum heart rate during physical training corresponded to $60-80 \%$ of the maximum heart rate reached during the cardiopulmonary test. Oxygen saturation had to be maintained over $85 \%$. Training continued for 30 minutes a day, 5 days a week, at home, for the following 15 weeks [9].

In addition to physical training, the patients received psychotherapy, in order to improve their own perception of their abilities as well as physical limitations. Psychological support was offered to all participants. The program was carefully supervised by physiotherapists, rehabilitation medicine specialists and experts in pulmonary hypertension. Oxygen saturation and heart rate were closely monitored during training and helped to adjust the intensity of training. When oxygen saturation decreased to less than $90 \%$ during training, patients received oxygen supplementation (3-10 1/min) during the exercise. Those patients who were on long-term oxygen therapy (16-24 hours/day) before their inclusion in the study, remained on oxygen therapy throughout the training program. On their discharge from hospital, after 3 weeks, the patients received an individualized training manual and a cycle ergometer to be used at home [9].

This study showed that physical training can improve the main prognostic parameters even in WHO functional class IV patients. Quality of life, the 6minute walk test, maximum oxygen consumption, 
WHO functional class, physical capacity, oxygenation, pulse and other parameters of the cardiopulmonary test were significantly improved after 3 and 15 weeks in all patients with pulmonary hypertension regardless of their initial functional class [9].

Compared to the beginning of the study, the mean 6 minute walk test significantly improved after 3 and 15 weeks [5]. A significant improvement of the WHO functional class was registered. After 3 weeks of training, $22 \%$ of WHO functional class IV patients moved to class III, and $6 \%$ moved from WHO functional class III to II [5]. After 3 weeks of training, the mean heart rate, the mean diastolic blood pressure value and the mean pulmonary artery pressure value at rest were significantly reduced. Furthermore, physical exercise and respiratory training significantly improved quality of life parameters such as: physical functioning, role physical, role emotional, social functioning, mental health and vitality [9]. During the first 3 weeks of the rehabilitation program that was conducted in hospital, adverse effects occurred in $13.6 \%$ of the patients. In $4.4 \%$ of these, the adverse effects were severe, including syncope in 2 patients and presyncope in 6 patients [9]. Thus, the results of this study indicate that physical exercise added to standard therapy in pulmonary hypertension is effective, but not completely harmless and requires careful supervision and monitoring.

Rehabilitation programs should be individualized. Ideally, supervised training programs should be conducted 3 times a week, and unsupervised training programs 2 times a week. However, in practice, supervised programs are carried out 2 times a week and unsupervised programs 3 times a week, at a $60 \%$ to $70 \%$ VO2peak intensity. It should be emphasized that a high intensity of physical exercise has beneficial effects, but decreases patients' adherence to the programs. The duration of the programs should be at least 6 weeks [17]. They should be initiated when patients are stable. In the first period, they will take place under supervision in an inpatient and/or outpatient setting, and subsequently at home (homebased rehabilitation).

In conclusion, cardiopulmonary rehabilitation programs represent an essential component of the management of chronic cor pulmonale. They contribute to the improvement of the exercise capacity, symptoms, and quality of life.

\section{References}

1. Postma DS, Bush A, van den Berge M. Risk factors and early origins of chronic obstructive pulmonary disease. Lancet 2015; 385(9971): 899-909.

2. http://www.who.int/news-room/factsheets/detail/chronic-obstructive-pulmonarydisease-(copd)

3. Konstam MA, Kiernan MS, Bernstein D, Bozkurt B, Jacob M, Kapur NK, et al. Evaluation and Management of Right-Sided Heart Failure: A Scientific Statement From the American Heart Association. Circulation 2018; 137(20): e578-e622.

4. Weitzenblum E; Chaouat A, Chron Respir Dis. 2009; 6(3):177-85, 1479-9731

5. Badesch DB, Champion HC, Sanchez MA, Hoeper MM, Loyd JE, Manes A, McGoon M, Naeije R, Olschewski H, Oudiz RJ, Torbicki A. Diag $\neg$ nosis and assessment of pulmonary arterial hypertension. J Am Coll Cardiol 2009;54(1 Suppl):S55-S66.

6. Farber HW, Loscalzo J. Pulmonary arterial hypertension. N Engl J Med 2004;351(16):1655-1665.

7. Galie N, Humbert M, Vachieryc JL, Gibbs s, Lang I, Torbicki A, Simonneaua G, Peacocka A, Vonk Noordegraafa A, Beghettib M, Ghofrania A et al. 2015 ESC/ERS Guidelines for the diagnosis and treatment of pulmonary hypertension - web addenda, European Heart Journal 2015; 1-13.

8. Grunig E, Ehlken N, Ghofrani A, Staehler G, Meyer FJ, Juenger J, Opitz CF, Klose H, Wilkens H, Rosenkranz S, Olschewski H, Halank M. Ef $\neg$ fect of exercise and respiratory training on clinical progression and survival in patients with severe chronic pulmonary hypertension. Respiration 2011;81(5):394-401.

9. Grunig E, Lichtblau M, Ehlken N, Ghofrani HA, Reichenberger F, Stae $\neg$ hler G, Halank M, Fischer C, Seyfarth HJ, Klose H, Meyer A, Sorichter S, Wilkens H, Rosenkranz S, Opitz C, Leuchte H, Karger G, Speich R, Nagel C. Safety and efficacy of exercise training in various forms of pulmonary hypertension. Eur Respir J 2012a;40(1):84-92. 
10. Chan L, Chin LM, Kennedy M, Woolstenhulme JG, Nathan SD, Wein $\neg$ stein AA, Connors G, Weir NA, Drinkard B, Lamberti J, Keyser RE. Benefits of intensive treadmill exercise training on cardiorespiratory function and quality of life in patients with pulmonary hypertension. Chest 2013;143(2):333-343.

11. Verma S, Cardenas-Garcia J, Mohapatra PR, Talwar A. Depression in pul $\neg$ monary arterial hypertension and interstitial lung diseases. $\mathrm{N}$ Am J Med Sci 2014;6(6):240-249.

12. Talwar A, Sahni S, John S, Verma S, CardenasGarcia J, Kohn N. Effects of pulmonary rehabilitation on Fatigue Severity Scale in patients with lung disease. Pneumonol Alergol Pol 2014;82(6):534-540.

13. Sahni S, Capozzi B, Iftikhar A, Sgouras V, Ojrzanowski M, Talwar A. Pulmonary rehabilitation and exercise in pulmonary arterial hypertension: An underutilized intervention. Journal of Exercise Rehabilitation 2015;11(2):74-79

14. Spruit MA, Singh SJ, Garvey C, ZuWallack R, Nici L, Rochester C; ATS/ERS Task Force on Pulmonary Rehabilitation. An official American Thoracic Society/European Respiratory Society statement: key con $\neg$ cepts and advances in pulmonary rehabilitation. Am J Respir Crit Care Med 2013;188(8):e13-64.

15. Galie N, Humbert M, Vachieryc JL, Gibbs s, Lang I, Torbicki A, Simonneaua G, Peacocka A, Vonk Noordegraafa A, Beghettib M, Ghofrania A et al. 2015 ESC/ERS Guidelines for the diagnosis and treatment of pulmonary hypertension. European Heart Journal 2016; 37; 69-113.

16. Mereles D, Ehlken N, Kreuscher S, Ghofrani S, Hoeper MM, Halank M, Meyer FJ, Karger G, Buss J, Juenger J, Holzapfel N, Opitz C, Winkler J, Herth FF, Wilkens H, Katus HA, Olschewski H, Grünig E. Exercise and respiratory training improve exercise capacity and quality of life in patients with severe chronic pulmonary hypertension. Circulation 2006;114(14):1482-1489.

17. Nici L, Donner C, Wouters E, Zuwallack R, Ambrosino N, Bourbeau $\mathrm{J}$ et al. American Thoracic Society/European Respiratory Society statement on pulmonary rehabilitation. Am J Respir Crit Care Med 2006; 173(12):1390-413. 